\title{
Incidence of first onset alcoholism among Taiwanese aborigines
}

\author{
WEI J. CHEN AND ANDREW T. A. CHENG ${ }^{1}$ \\ From the Institute of Biomedical Sciences, Academia Sinica; and Institute of Epidemiology, \\ College of Public Health, National Taiwan University, Taipei, Taiwan.
}

\begin{abstract}
Background. An initial prevalence survey of mental disorders among 993 subjects aged 15 and above randomly drawn from four major Taiwanese aboriginal groups (the Atayal, Ami, Bunun and Paiwan) was conducted from 1986 to 1988. The incidence of alcoholism was investigated in a followup survey from 1990 to 1992.
\end{abstract}

Methods. Both surveys employed a semi-structured clinical interview with satisfactory reliability for case identification, and DSM-III-R as the diagnostic criteria for alcohol use disorders. The estimation of incidence rates of first onset alcoholism (alcohol abuse or dependence) was based on person-years at risk of 499 subjects who did not have any lifetime diagnosis of such morbidity at phase I.

Results. The follow-up rate was $99 \cdot 6 \%$ and only four subjects among the survivors were not found. The age-standardized annual incidence rates of alcoholism ranged from 2.8 to $4.9 \%$ among the four aboriginal groups, and the rank order of rates was consistent with that of prevalences among these groups. The incidence rates of alcoholism were the highest among adolescents and young adults in men, and among the middle-aged in women.

Conclusions. High rates of first onset alcoholism among the Taiwanese aborigines indicate an interaction of sociocultural and biological factors in the development of such morbidity.

\section{INTRODUCTION}

There have been many studies of the prevalence of alcoholism (Warheit \& Auth, 1985; Helzer, 1987). However, to estimate the underlying 'force of morbidity' (Miettinen, 1976) or incidence rate in a population and assess potential risk factors with clear temporality for alcoholism, only prospective cohort studies can accomplish these. As for mental illness in general, there have been very few reports of the incidence of alcoholism.

Conceptually, the incidence of mental illness can be differentiated into first incidence and total incidence (Kleinbaum et al. 1982; Eaton et al. 1985). For first incidence, the event is defined

1 Address for correspondence: Professor Andrew T. A. Cheng, Division of Epidemiology and Public Health, Institute of Biomedical Sciences, Academia Sinica, Taipei, Taiwan. as the first occurrence of the disorder in a subject's lifetime and hence the population at risk are those who have never had any episodes of the disorder at the beginning of the study. In contrast, for total incidence, recurrent episodes are included in the definition of the event, and subjects without active symptoms are counted as the population at risk. Total incidence rate is affected not only by mortality but also by duration of episodes (Eaton et al. 1985). Because alcoholic persons tend to have an increased mortality and the duration of an alcoholic episode is usually difficult to determine, we consider only the first incidence of alcoholism and will refer to it as incidence hereafter.

Early retrospective cohort studies of alcoholism provided only estimates of lifetime expectancy and not the incidence rate itself (Fremming, 1951; Helgason, 1964). Besides, 
these retrospective cohort studies might have been influenced by the accuracy of subjects' recall of remote events or existing records. There have been only two reports of annual incidence rate of alcoholism so far (Öjesjö et al. 1982; Eaton et al. 1989).

Forty years ago, the lifetime prevalence of alcoholism detected by clinical interview among the Taiwanese aborigines was very low, ranging from 0 to $0 \cdot 16 \%$ (Rin \& Lin, 1962). In that survey only severe alcoholics with profound social or work impairment were counted while 'habitual drinkers ... at a reduced level of adjustment' were not. In a recent survey (1986-8) using a semi-structured standardized clinical interview and DSM-III-R criteria, we found that the prevalence of alcohol use disorders among four major aboriginal groups arise prominently, ranging from 44.5 to $54.5 \%$ (Cheng $\&$ Chen, 1995). Despite the considerable differences in research methodology between the two surveys, the evidence does imply a huge increase of alcoholism in these populations. Causes for such a dramatic change will be important clues to the aetiology of alcoholism. The present study reports the sex- and agespecific incidence rate of alcohol use disorders among these groups on the basis of a follow-up study conducted 4 years later (1990-92). The evaluation of risk factors for development of alcoholism will be presented in a separate article.

\section{METHOD \\ Study populations}

In Taiwan, there are nine aboriginal groups, all of which are descended from Malayo-Polynesian stock and speak languages stemming from the Austronesian family. The combined population of these nine groups was about $321900(1 \cdot 7 \%$ of the total population of Taiwan) in 1986. The groups can be distinguished from each other not only by geographic distribution, but also by extensive differences in language, sociocultural institutions, and physiognomy (Chai, 1967). Before Taiwan was returned to the Nationalist Chinese Government in 1945 after 50 years of Japanese rule, all nine aboriginal groups maintained a great deal of their indigenous sociocultural heritage in their agrarian societies. This picture did not change much until the past three decades, during which rapid acculturation has taken place among them under tremendous socioeconomic pressure from the Han Chinese in Taiwan.

Study subjects were those who participated in the Taiwan Aboriginal Study Project (TASP) from the four groups (the Atayal, Ami, Bunun and Paiwan). The objectives and methodology of TASP have been described in detail elsewhere (Cheng \& Hsu, 1992; Cheng \& Chen, 1995). In brief, two waves of interviews were conducted among the randomly chosen subjects in 1986-8 and 1990-92, respectively.

\section{Two waves of interviews}

In phase I of TASP, a random sample of individuals of both sexes aged 15 years and above was drawn from each of the four ethnic groups. The population size of the four groups in 1986 was about 75400 for the Atayal, 121200 for the Ami, 35800 for the Bunun and 59100 for the Paiwan. For each group, four villages were selected via multistage random sampling with probability proportional to population size (Sudman, 1976). All selected samples were of nearly equal size (242 to 253 for the four groups) and the total sample size was 993 subjects. Since respondents in each ethnic group had equal probabilities of selection according to this method, the resulting sample was self-weighting and no adjustment was needed for the estimation of prevalence or incidence. However, the incidence of four groups combined was weighted by each group's population size. In view of the high social mobility of aborigines, the sample frame was constructed from a household survey conducted in each village which included all living members who could be contacted in Taiwan. The response rates in the four aboriginal samples were between $96.5 \%$ and $99.2 \%$. The respondents were found to be representative of their populations in terms of age, sex, marital status and educational level (Cheng \& Hsu, 1992).

The fieldwork at phase I consisted of continuing ethnographic observation of the survey communities and detailed interviews of sample subjects. The latter were conducted in terms of a health care visit, and used inventories covering physical health, illness behaviour, psychosocial stress, sociodemographic information and the extent of acculturation. Psychiatric assessment was conducted by Cheng, who also interviewed 
the elderly, senior teachers, priests, health workers, and other community key-informants to understand the history, socioeconomic and cultural changes and alcohol drinking behaviour of these people.

In each survey community, one or two aborigines with college education were selected as local principal assistants (LPAs). Most of them were public health nurses who provide primary health services. They gave substantial help in constructing the sample frame, in establishing trustful relationships between respondents and investigators, and in interpreting.

At phase II, the same clinical interview for alcoholism was conducted by Cheng and two well-trained research assistants according to the same strategy. All interviewers were not blind to subjects' baseline status because providing relevant health information was essential in motivating subjects' participation in the follow-up. Furthermore, the fieldwork used a follow-up inventory covering changes in various life domains encountered since phase I. Blood samples for laboratory tests and molecular genetic studies were collected by LPAs with informed consent a few weeks before the interview. During the fieldwork, reports of the tests were first given to the subjects with medical explanation and useful advice. For deceased subjects, the research team obtained information about their alcohol drinking and health conditions before death, and the causes of death from their close relatives, neighbours, LPAs, and local health authorities. Any medical records available were obtained from hospitals and clinics.

\section{Case ascertainment}

A semi-structured clinical interview on alcoholism was developed and used in the two phases as part of the psychiatric assessment. The design and standardization of this interview was based on our preliminary participating observations of the drinking attitudes and behaviour among these four aboriginal groups. The instrument was described in detail elsewhere (Cheng \& Chen, 1995). In brief, it covers all the symptoms and their duration that are used as diagnostic criteria of alcohol use disorders in both the ICD10 (World Health Organization, 1993) and the DSM-III-R (American Psychiatric Association, 1987).
However, semantic equivalents were used for some of the items in our instrument to ensure cross-cultural validity. For instance, risk-taking behaviour for the mountain aborigines often involves walking near the edges of cliffs after heavy drinking. Relevant items were, therefore, modified according to the real situation, and both respondents and the village people were asked to evaluate the degree of danger of an individual's risk-taking behaviour as a crosscheck. Verbal and physical aggression after heavy drinking is often denied by respondents when inquired by non-aboriginal interviewers. The assessment of social and legal problems due to alcohol intake, therefore, substantially relied on reports of respondents' family members and LPAs.

In a reliability study of the semi-structured interview, three raters (two psychiatrists and one physician) interviewed 24 Han Chinese subjects. The three raters took turns to interview a subject and the others rated simultaneously. Possible diagnoses included no alcohol use disorder, alcohol abuse and alcohol dependence. The generalized kappa (three raters by three categories) (Bartko \& Carpenter, 1976) for the lifetime diagnoses was 0.80 according to the DSM-III-R. A further examination of the items pertaining to the diagnosis of alcoholism revealed that the main source of disagreement came from items regarding physical illnesses caused by drinking (kappa $=0.76)$ and the ability to control drinking $(\mathrm{kappa}=0 \cdot 68)$. All the other items had excellent inter-rater reliability (kappa $>0 \cdot 90$ ). Research assistants were trained by Cheng to have good inter-rater reliability with him before their field work, with $100 \%$ agreement for the diagnoses of 18 subjects (six for each diagnosis).

Although a lifetime drinking history had been taken at phase I by Cheng, the lifetime alcohol drinking status of $25(2.5 \%)$ subjects assessed at phase I were changed according to further information gathered at phase II from respondents and/or their family members. Among them, $16(1.6 \%)$ subjects were changed from normal to abuse or dependence and nine $(0.9 \%)$ from abuse to dependence. Sixteen of the 25 subjects gave more information because they had been told that they had physical conditions related to alcohol drinking according to our laboratory tests performed at phase II, or 
because they had accidents with severe injury since phase I. The remaining nine had already died of alcohol complications (liver conditions, tuberculosis, vascular stroke, accident, and suicide). Their family members, who were not available at phase I, provided clear evidence for their diagnosis of alcoholism in the phase II interview.

In this report, alcoholism refers to the diagnoses of alcohol abuse or dependence according to the DSM-III-R. We operationally defined the age at onset of alcoholism as the first time when a subject's symptoms fulfilled the criteria of alcohol abuse or dependence. If a dead subject was found to have been alcoholic, then the subject's age at onset was determined from information obtained from his or her proxies.

\section{Statistical analysis}

In the calculation of incidence rates, the population at risk included only those subjects who did not have any lifetime diagnosis of alcoholism at phase I. The person-year was partitioned into three age intervals: $15-24,25-44$, and $\geqslant 45$ years. A subject ceased to contribute to the person-year when he died or became alcoholic. Under the assumption of Poisson distribution, the standard error of an incidence rate was computed as $n /(\text { py })^{2}$, where $n$ is the number of new cases and py is the person-years at risk. We used a direct method to standardize the incidence rates for age. To make the incidence rates comparable across countries, the truncated age distribution of the world population in the same age-range was used as the standard $(25.4 \%$, $35.8 \%$, and $38.8 \%$ respectively). The variance of the standardized rate was computed by the formula $\sum_{i=1}^{3} w_{i}^{2} \operatorname{Var}\left(I R_{i}\right)$, where $w_{i}$ is the weight and $I R_{i}$ the incidence rate for the $i$ th age group (Breslow \& Day, 1987). In the estimation of the incidence rate for all aborigines together, the relative proportions of the population size for the four groups were used as weights in applying the method of direct standardization.

By assuming that the incidence rate was constant within each age interval, cumulative risk up to $j$ th age group was calculated by the formula $C I_{j}=1-\exp \left(-\sum_{i=1}^{j} I R_{i} D_{i}\right)$, where $D_{i}$ is the length of the $i$ th age group and $I R_{i}$ the incidence rate of the $i$ th age interval. The standard error of the cumulative risk was modified from standard error of the standardized rate with weight being replaced by length of age interval. The delta method (Rice, 1988) was then applied to derive the standard error of the cumulative risk.

\section{RESULTS}

The average follow-up period was $4 \cdot 3 \pm 0 \cdot 5$ years for the four groups. During the follow-up period, 59 subjects died $(25,11,9$, and 14 for the Atayal, Ami, Bunun and Paiwan respectively). Of the survivors, only four subjects (three Atayal and one Ami) were lost to follow-up. The follow-up rate was $99 \cdot 6 \%$.

For the 499 subjects who did not demonstrate any alcohol use disorder at phase I, 14 to $30 \%$ of men and 7 to $13 \%$ of women became alcohol abusers during the follow-up period (Table 1). Only 3 to $6 \%$ of men and 0 to $2 \%$ of women were found to have alcohol dependence during this period. Because the number of new cases of alcohol dependence was small for these subjects, abuse and dependence were combined in the following calculation.

The incidence rates of alcoholism for men decreased as age increased except for the Bunun (Table 2). For women, the highest incidence rates among two groups (Ami and Bunun) did not occur at the youngest age interval, but at 25-44 years (Table 3 ). For the incidence rates of all ages together for men, the highest rates

Table 1. Alcoholic status at phase II (1990-92) for 499 subjects without alcohol use disorders at phase I (1986-8) among the four aboriginal groups in Taiwan

\begin{tabular}{|c|c|c|c|c|c|c|}
\hline \multirow[b]{2}{*}{ Groups } & \multicolumn{2}{|c|}{ None } & \multicolumn{2}{|c|}{ Abuse } & \multicolumn{2}{|c|}{ Dependence } \\
\hline & $N$ & $(\%)$ & $N$ & $(\%)$ & $N$ & $(\%)$ \\
\hline \multicolumn{7}{|l|}{ Atayal } \\
\hline $\operatorname{Men}(N=38)$ & 27 & (71) & 11 & (29) & 0 & $(0)$ \\
\hline Women $(N=78)$ & 68 & (87) & 10 & (13) & 0 & $(0)$ \\
\hline \multicolumn{7}{|l|}{ Ami } \\
\hline $\operatorname{Men}(N=38)$ & 31 & $(82)$ & 7 & (18) & 0 & $(0)$ \\
\hline Women $(N=101)$ & 92 & (91) & 9 & (9) & 0 & $(0)$ \\
\hline \multicolumn{7}{|l|}{ Bunun } \\
\hline $\operatorname{Men}(N=40)$ & 27 & $(68)$ & 12 & $(30)$ & 1 & (3) \\
\hline Women $(N=70)$ & 63 & $(90)$ & 7 & (10) & 0 & $(0)$ \\
\hline \multicolumn{7}{|l|}{ Paiwan } \\
\hline $\operatorname{Men}(N=36)$ & 29 & $(81)$ & 5 & (14) & 2 & (6) \\
\hline Women $(N=98)$ & 89 & (91) & 7 & (7) & 2 & (2) \\
\hline
\end{tabular}


occurred in Bunun, followed by Atayal, Paiwan and Ami (Table 4). For women, the differences among the four groups were much smaller; but the Ami still had the lowest rate, while the Atayal had the highest.

Averaged annual incidence rates of alcoholism for all aborigines together were calculated by weighting the incidence rates of the four groups (Fig. 1). Unlike for men, whose rates decreased as age increased, in women the rates increased to a maximum at age interval 25-44 years, and

Table 2. Male age-specific incidence rates ( \pm standard error) of alcoholism among the four aboriginal groups in Taiwan, 1986-90

\begin{tabular}{lrccc}
\hline $\begin{array}{l}\text { Age group } \\
\text { (years) }\end{array}$ & $\begin{array}{c}\text { Number } \\
\text { at risk }\end{array}$ & $\begin{array}{c}\text { Person-years } \\
\text { at risk }\end{array}$ & Cases & $\begin{array}{c}\text { Annual incidence } \\
\left(10^{-3}\right)\end{array}$ \\
\hline $\begin{array}{c}\text { Atayal } \\
15-24\end{array}$ & 20 & $68 \cdot 3$ & 8 & $117 \pm 41$ \\
$25-44$ & 8 & $34 \cdot 4$ & 2 & $58 \pm 41$ \\
$\geqslant 45$ & 10 & $36 \cdot 0$ & 1 & $28 \pm 27$ \\
Ami & & & & \\
$15-24$ & 17 & $53 \cdot 3$ & 5 & $94 \pm 42$ \\
$25-44$ & 12 & $55 \cdot 3$ & 2 & $36 \pm 26$ \\
$\geqslant 45$ & 9 & $47 \cdot 2$ & 0 & 0 \\
Bunun & & & & \\
$15-24$ & 17 & $43 \cdot 9$ & 6 & $137 \pm 56$ \\
$25-44$ & 17 & $61 \cdot 5$ & 4 & $65 \pm 33$ \\
$\geqslant 45$ & 6 & $19 \cdot 7$ & 3 & $153 \pm 88$ \\
Paiwan & & & & \\
$15-24$ & 12 & $34 \cdot 5$ & 4 & $116 \pm 58$ \\
$25-44$ & 13 & $42 \cdot 2$ & 2 & $47 \pm 33$ \\
$\geqslant 45$ & 11 & $45 \cdot 0$ & 1 & $22 \pm 22$ \\
\hline \hline
\end{tabular}

Table 3. Female age-specific incidence rates ( \pm standard error) of alcoholism among the four aboriginal groups in Taiwan, 1986-90

\begin{tabular}{lcccc}
\hline $\begin{array}{l}\text { Age group } \\
\text { (years) }\end{array}$ & $\begin{array}{c}\text { Number } \\
\text { at risk }\end{array}$ & $\begin{array}{c}\text { Person-years } \\
\text { at risk }\end{array}$ & Cases & $\begin{array}{c}\text { Annual incidence } \\
\left(10^{-3}\right)\end{array}$ \\
\hline $\begin{array}{c}\text { Atayal } \\
15-24\end{array}$ & 25 & $86 \cdot 4$ & 6 & $69 \pm 28$ \\
$25-44$ & 23 & $102 \cdot 4$ & 4 & $39 \pm 20$ \\
$\geqslant 45$ & 30 & $80 \cdot 8$ & 0 & 0 \\
Ami & & & & \\
$15-24$ & 25 & $99 \cdot 6$ & 2 & $20 \pm 14$ \\
$25-44$ & 37 & $147 \cdot 6$ & 7 & $47 \pm 18$ \\
$\geqslant 45$ & 39 & $132 \cdot 9$ & 0 & 0 \\
Bunun & & & & \\
$15-24$ & 28 & $95 \cdot 2$ & 2 & $21 \pm 15$ \\
$25-44$ & 22 & $81 \cdot 1$ & 5 & $62 \pm 28$ \\
$\geqslant 45$ & 20 & $46 \cdot 9$ & 0 & 0 \\
Paiwan & & & & \\
$15-24$ & 32 & $95 \cdot 0$ & 4 & $42 \pm 21$ \\
$25-44$ & 23 & $103 \cdot 1$ & 4 & $39 \pm 19$ \\
$\geqslant 45$ & 43 & $104 \cdot 9$ & 1 & $10 \pm 10$ \\
\hline \hline
\end{tabular}

Table 4. The age standardized annual incidence rates $\left(10^{-3}\right)$ ( \pm standard error) of alcoholism among the four aboriginal groups in Taiwan, 1986-90: a comparison with other studies

\begin{tabular}{lrcc}
\hline \hline Ethnic groups & Men & Women & Total \\
\hline Aborigines in Taiwan & & & \\
$\quad$ Atayal & $61 \pm 21$ & $32 \pm 10$ & $41 \pm 9$ \\
Ami & $37 \pm 14$ & $22 \pm 7$ & $28 \pm 7$ \\
$\quad$ Bunun & $117 \pm 39$ & $27 \pm 11$ & $49 \pm 11$ \\
$\quad$ Paiwan & $55 \pm 21$ & $28 \pm 10$ & $34 \pm 9$ \\
$\quad$ All & $57 \pm 10$ & $26 \pm 5$ & $35 \pm 4$ \\
Lundby, Sweden (1957-72)* & $4 \pm 0 \cdot 7$ & & \\
Four cities in USA (1981-2) $\dagger$ & $36 \cdot 7 \pm 5 \cdot 4$ & $6 \cdot 3 \pm 1 \cdot 3$ & $18 \cdot 2 \pm 3 \cdot 6$ \\
\hline \hline
\end{tabular}

* Data from Öjesjö et al. (1982); age standardized to the world population.

$\dagger$ Data from Eaton et al. (1989); age standardized to the world population.

then dropped to a very low rate. The cumulative risk up to age of 25 years was $67 \%$ for men and $31 \%$ for women. The risks up to age 65 years were $93 \%$ for men and $74 \%$ for women (Fig. 2).

\section{DISCUSSION}

\section{Methodological issues}

Any prospective cohort study of alcoholism conducted in the community involves several difficulties in methodology that deserve discussion. A considerable proportion of nonrespondents are likely to have drinking problems. Thus, either non-response in the initial survey or loss of contact in the follow-up would make the estimate for incidence rate of alcoholism less precise. Another difficulty is that the number of new cases tends to be low, given the usual rate of alcoholism. Although a large number of subjects or a long period of follow-up would allow for enough new cases, it would also increase the complexity of the investigation. For example, if the interval between two interviews were long then the subject might be asked to recall a remote event, resulting in questionable accuracy. This issue especially concerns the determination of age at onset, which is essential in the calculation of incidence rates. Of course one solution would be to increase the follow-up frequency in the interval, but the cost would increase too. Furthermore, the quality of information collected may vary across interviews and make the diagnosis unreliable. For example, the information collected during phase II might 


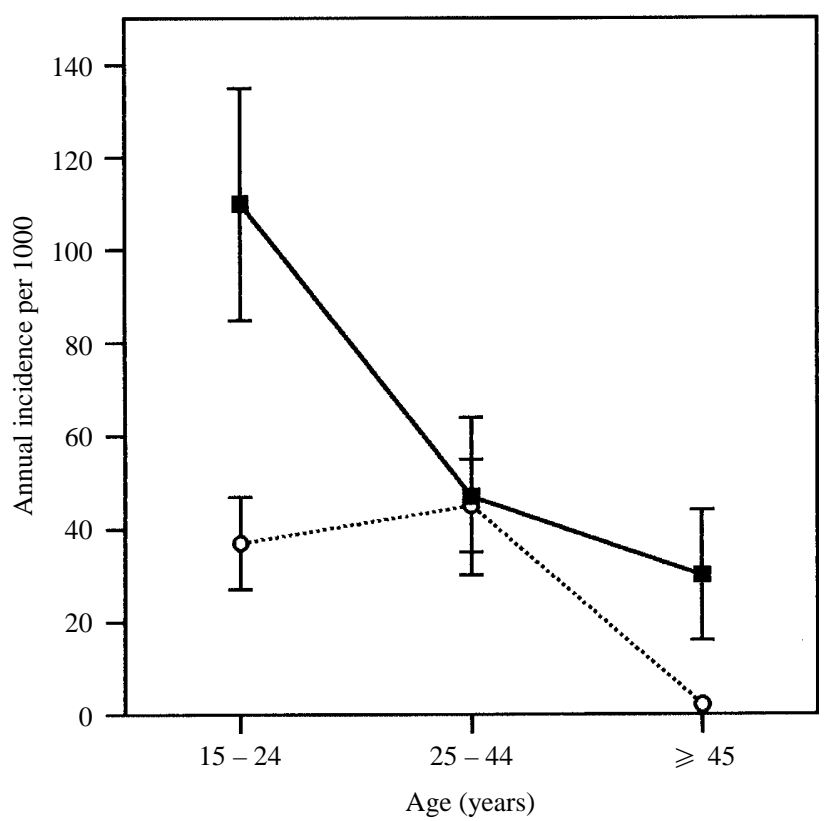

FIG. 1. Incidence rates with their standard errors indicated by vertical bars, by age group, of alcoholism in the four aboriginal groups in Taiwan, 1986-90, for men (ם- $\mathbf{-})$ and women $(\bigcirc--\bigcirc)$.

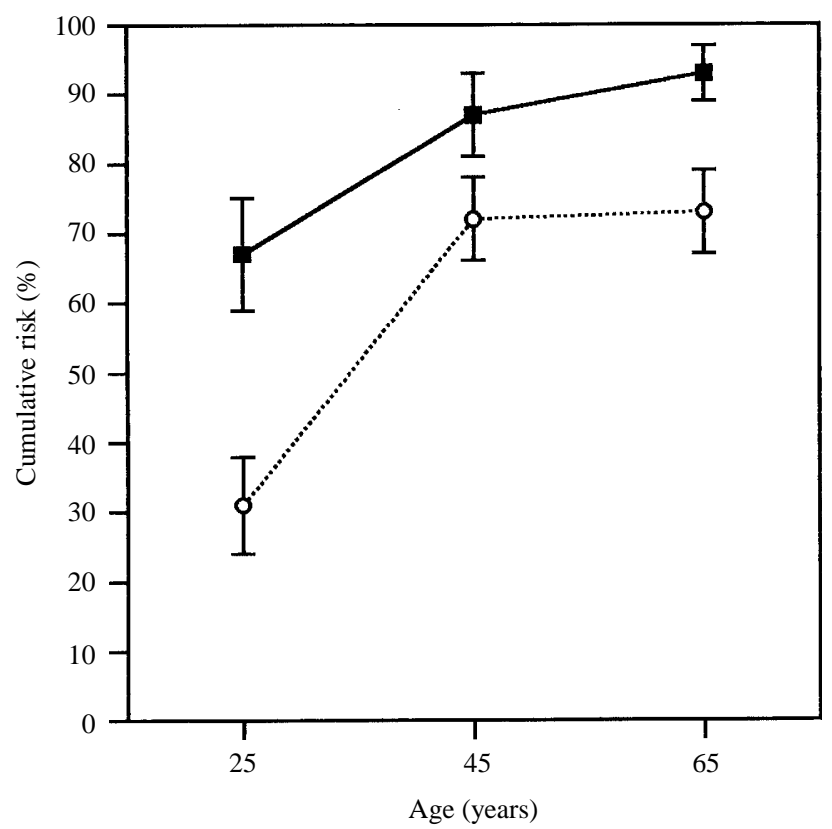

FIG. 2. Cumulative risks with their standard errors indicated by vertical bars, by age group, of alcoholism in the four aboriginal groups in Taiwan, 1986-90, for men $(\mathbf{\square - \square})$ and women $(\bigcirc--\bigcirc)$.

conflict with that from phase I, as reported in the Epidemiological Catchment Area (ECA) study (Eaton et al. 1989) and ours.
Several features of this study might help overcome the problems discussed above. The completeness of the initial survey and follow-up 
achieved in this study is similar to that in the Lundby Study (Öjesjö et al. 1982), in which the follow-up rate was almost $100 \%$. Thus the concern about attrition or response bias is minimized in these two studies. In contrast, in the ECA study (Eaton et al. 1989), the followup rate was about $80 \%$.

The case ascertainment in our study was based on a reliable and semi-structured clinical interview and the diagnosis was made according to operational criteria. Apart from interviewing the subjects themselves, information from other sources was collected. In this respect our study is similar to the Lundby Study, whereas in the ECA study diagnoses were based solely on information collected from the structured Diagnostic Interview Schedule. The multiinformants approach helped us discover at phase II that there were $1.6 \%$ false-negatives at phase I. Ignorance of such misclassification would lead to underestimate of prevalence at phase I and overestimate of incidence at phase II.

Both the Lundby Study and the ECA Study used the DSM-III criteria, which is more stringent than the DSM-III-R applied in this study. The former requires either tolerance or withdrawal for alcohol dependence, and a pathological pattern of alcohol use for alcohol abuse. The threshold for alcohol abuse in DSMIII-R (e.g. social impairment or risk-taking behaviour alone is enough) tends to be lower than that in DSM-III.

\section{Gender and trend of age-specific incidence}

In examining the age pattern of incidence of alcoholism, the four groups were combined because the patterns were similar for men and the number of cases were too sparse for women within each group. For male aborigines, the incidence rates of alcoholism were highest among adolescents and young adults (15-24 years old). As men grew older, the incidence rate of alcoholism decreased. This pattern is consistent with those of the Lundby Study and the ECA study. The occurring of peak male incidence at young ages in this study might be in part due to the fact that most of the new cases were alcohol abusers. People who have alcohol dependence usually have already undergone a certain time of abuse, i.e. the disorder of alcohol dependence takes longer to develop. In the Lundby Study, when alcohol dependence alone was considered, the peak of its incidence rate occurred at an older age (20-29 years) than that for alcohol abuse (10-19 years) (Öjesjö et al. 1982).

Unlike male aborigines, the highest incidence rate of alcoholism for female aborigines occurred in the middle ages (25-44 years), and then decreased substantially after that. This pattern is consistent with that observed for prevalences of alcohol abuse in our previous report (Cheng \& Chen, 1995). In contrast, the incidence rates of alcoholism for women in the ECA study were highest among adolescents and young adults (18-28 years old) (Eaton et al. 1989). The difference might be related to the tremendous stress of marital life for aboriginal women, as we pointed out previously (Cheng \& Chen, 1995). Although the extent of these stresses may differ between women of these four ethnic groups, it is difficult to examine this for individual aboriginal groups because of the limited number of new cases in each group.

\section{Cross-cultural comparison of incidence}

Among the four aboriginal groups, the Bunun had the highest incidence rate of alcoholism, followed by the Atayal, the Paiwan and the Ami. This order was consistent with that of prevalences among the four aboriginal groups (Cheng \& Chen, 1995). Given that prevalence reflects both the incidence and duration of a disease, this result implies that the duration of alcoholism may be similar for all the groups. Indeed, there was no significant difference in duration of alcoholism assessed among the four groups at phase I (Cheng \& Chen, 1995). What accounted for the differences in the prevalences of alcoholism among the four groups therefore lay in the incidence rates.

Interestingly, the rank order of incidence rates among the four aboriginal groups follows the reverse order of the degree of acculturation. It is a consensus among most anthropologists in Taiwan that the Ami are the most acculturated, followed by the Paiwan, the Atayal and the Bunun. This is supported by the finding of a significantly higher educational level in the Ami and Paiwan than in the other two groups, in both sexes (Cheng \& Hsu, 1992). However, inference from such ecological comparisons needs to be validated by individual acculturation data.

The incidence rates of alcoholism among the 
four aboriginal groups were much higher than those reported in Sweden or the United States. The less stringent DSM-III-R criteria of alcohol abuse might account for in part the higher figures in our sample. However, we think the effect of criteria difference is minor since the prevalences of DSM-III-R alcohol dependence in these aborigines were similarly much higher than those of the United States (Cheng \& Chen, 1995). Interestingly, the annual incidence rate among the male Ami $\left(37 \times 10^{-3}\right)$ was similar to that in the United States $\left(36.7 \times 10^{-3}\right)$ while the rates among the men of the other three aboriginal groups and the women of all the four groups were much higher. Although we do not have data on incidence rates among Han Chinese, the rates should be much lower than those among aborigines on the basis of their prevalences (Helzer et al. 1990).

Given that the Ami is the group most acculturated to the Han Chinese culture but the incidence rate of their men is similar to that in the United States rather than the presumed incidence rate of Han Chinese, we suggest two possibilities. First, the genetic vulnerability to alcoholism among the Taiwanese aborigines may be more similar to that of Caucasians than to that of Han Chinese. For example, the frequency of the defective allele of acetaldehyde dehydrogenase (ALDH) gene, ALDH2*2, among the Atayal, Ami, Bunun and Paiwan are $0.03,0.02,0.02$, and 0.05 respectively, close to that among Caucasians (0.013-0.02) while much lower than among the Han Chinese (0.24) (Chen et al. 1997). Secondly, Ami men might undergo similar stress as Han Chinese or Caucasian men do. However, Ami women and aborigines of the other three groups might face more stress than their counterparts of Han Chinese or Caucasians, in addition to their possible genetic susceptibility.

\section{Cumulative risk}

Unlike an incidence rate, which refers to a population, a cumulative risk does have a direct interpretation on the individual level. Given the current incidence rate of alcoholism among the aborigines, the cumulative risks at various ages were very high. For comparison, the lifetime expectancy of alcoholism for men was $19 \cdot 3 \%$ in the Lundby Study (Öjesjö et al. 1982). However, as the lengths of the three age intervals in our calculation are large and hence the assumption that the incidence rate is constant within each interval may not hold, the estimates are preliminary.

All these data, along with the finding of increased mortality due to alcohol-related diseases, accidents and suicide (Cheng \& Hsu, 1992; Cheng, 1995), reflect clearly that the Taiwanese aborigines face a very serious health crisis. Further analyses of the potential risk factors and explanations of the alcoholism among them is being undertaken.

This work was supported by grants from the National Science Council, Taipei (NSC 75,76-0301-H002-28, NSC 78,79-0301-H002-40, NSC 83-0203-B001-102, NSC 84-2331-B001-046), and a grant from the Department of Health, Taiwan, ROC (DOH-80-03; DOH-81-111). The authors would like to acknowledge the hard work and excellent performance of our research assistants Misses J. C. Chang, C. L. Cheng, and J. Y. Kao, and LPAs in the fieldwork.

\section{REFERENCES}

American Psychiatric Association (1987). Diagnostic and Statistical Manual of Mental Disorders, 3rd edn-Revised. American Psychiatric Association: Washington, DC

Bartko, J. J. \& Carpenter, W. T., Jr (1976). On the methods and theory of reliability. Journal of Nervous and Mental Disease 163, 307-317.

Breslow, N. E. \& Day, N. E. (1987). Statistical Methods in Cancer Research. Volume II-The Design and Analysis of Cohort Studies. International Agency for Research on Cancer: Lyon.

Chai, C. K. (1967). Taiwan Aborigines: A Genetic Study of Tribal Variations. Harvard University Press: Cambridge, Mass.

Chen, W. J., Loh, E. W., Hsu, Y.-P. P., Chen, C. C., Yu, C. M., Cheng, A. T. A. (1997). Alcohol dehydrogenase (ADH) and aldehyde dehydrogenase (ALDH) genotypes and alcoholism among Taiwanese aborigines. Biological Psychiatry 41, 703-709.

Cheng, A. T. A. (1995). Mental illness and suicide: a case-control study in East Taiwan. Archives of General Psychiatry 52, 594-603.

Cheng, T. A. \& Chen, W. J. (1995). Alcoholism among four aboriginal groups in Taiwan: high prevalences and their implications. Alcoholism: Clinical and Experimental Research 19, 81-91.

Cheng, T. A. \& Hsu, M. (1992). A community study of mental disorders among four aboriginal groups in Taiwan. Psychological Medicine 22, 255-263.

Eaton, W. W., Weissman, M. M., Anthony, J. C., Robins, L. N., Blazer, D. G. \& Karno, M. (1985). Problems in the definition and measurement of prevalence and incidence of psychiatric disorders. In Epidemiologic Field Methods in Psychiatry: the NIMH Epidemiologic Catchment Area Program (ed. W. W. Eaton and L. G. Kessler), pp. 311-326. Academic Press: New York, NY.

Eaton, W. W., Kramer, M., Anthony, J. C., Dryman, A., Shapiro, S. \& Locke, B. Z. (1989). The incidence of specific DIS/DSM-III mental disorders: data from the NIMH Epidemiologic Catchment Area Program. Acta Psychiatrica Scandinavica 79, 163-178.

Fremming, K. H. (1951). The Expectation of Mental Infirmity in a Sample of the Danish Population: Occasional Papers on Eugenics (No. 7). Cassell: London. 
Helgason, T. (1964). Epidemiology of mental disorders in Iceland. Acta Psychiatrica Scandinavica 40 (Suppl. 173), 115-132.

Helzer, J. E. (1987). Epidemiology of alcoholism. Journal of Consulting and Clinical Psychology 55, 284-292.

Helzer, J. E., Canino, G. J., Yeh, E.-K., Bland, R. C., Lee, C. K., Hwu, H.-G. \& Newman, S. (1990). Alcoholism - North America and Asia. A comparison of population surveys with the Diagnostic Interview Schedule. Archives of General Psychiatry 47, 313-319.

Kleinbaum, D. G., Kupper, L. L. \& Morgenstern, H. (1982) Epidemiologic Research: Principles and Quantitative Methods. Lifetime Learning Publication: Belmont.

Miettinen, O. S. (1976). Estimability and estimation in case-referent studies. American Journal of Epidemiology 103, 226-235.

Öjesjö, L., Hagnell, O. \& Lanke, J. (1982). Incidence of alcoholism among men in the Lundby community cohort: Sweden, 1957-1972.
Probabilistic baseline calculations. Journal of Studies on Alcohol 43, 1190-1198

Rice, J. A. (1988). Mathematical Statistics and Data Analysis. Wadsworth \& Brooks/Cole Advanced Books \& Software: Pacific Grove, California.

Rin, H. \& Lin, T.-Y. (1962). Mental illness among Formosan aborigines as compared with the Chinese in Taiwan. Journal of Mental Science 108, 134-146.

Sudman, S. (1976). Applied Sampling. Academic Press: New York.

Warheit, G. J. \& Auth, J. B. (1985). Epidemiology of alcohol abuse in adulthood. In Psychiatry (vol. 3) (ed. J. O. Cavenar), pp. 1-18. Lippinott: Philadelphia, PA.

World Health Organization (1993). The ICD-10 Classification of Mental and Behavioural Disorders: Diagnostic Criteria for Research. World Health Organization: Geneva. 